\title{
Hava Kompresörü Verimliliğine Basınç Yükseltici Kullanımının Etkisinin İncelenmesi
}

\author{
Duran Arif Göçer ${ }^{1 *}$, Ömer Yiğit ${ }^{1}$, Mete Kalyoncu ${ }^{2}$ \\ ${ }^{1 *}$ Yıldız Pul Otomotiv Motor Parçaları Sanay A.Ş. , Konya, Türkiye (ORCID: 0000-0002-2215-1542) \\ ${ }^{2}$ Konya Teknik Üniversitesi, Mühendislik ve Doğa Bilimleri Fakültesi, Makine Mühendisliği Bölümü, Konya, Türkiye (ORCID: 0000-0002-2214-7631)
}

( $1^{\text {st }}$ International Conference on Computer, Electrical and Electronic Sciences ICCEES 2020 - 8-10 Ekim 2020)

(DOI: $10.31590 /$ ejosat.801905)

\begin{abstract}
ATIF/REFERENCE: Göçer, D.A. Yigit, Ö. \& Kalyoncu, M. (2020). Hava Kompresörü Verimliliğine Basınç Yükseltici Kullanımının Etkisinin İncelenmesi. Avrupa Bilim ve Teknoloji Dergisi, (Özel Sayı), 136-141.

$\ddot{O} \mathbf{z}$

Günümüzde hızla gelişim gösteren ekonomi, rekabetin de artmasını beraberinde getirmektedir. İşletmelerin daha verimli sonuçlar alması için enerji verimliliğinin gözden geçirilmesi gerekmektedir. Enerji verimliliği işletmelerde ürün başına düşen gereğinden fazla enerji sarfiyatının minimuma indirilmesi olarak tanımlanabilir. Birçok işletmenin basınçlı hava ihtiyacı, sistemlerin çalışması için mecburi zorunluluktur. Bu sebeple basınçlı havanın verimli kullanılması oldukça önem arz etmektedir.

Bu çalışmada, bir otomotiv fabrikasındaki basınçlı hava sisteminin verimliliği konusunda ölçümler sonucu yüksek basınç gerektiren ürün testleri için havanın hangi yollar ile daha verimli kullanılacağı üzerinde çalışmalar yapılmıştır. Hava yükseltici kullanımının hava kompresörü verimliliğini nasıl etkilediği incelenmiştir.
\end{abstract}

Anahtar Kelimeler: Basınçlı Hava Kompresörleri, Basınç Yükseltici, Enerji Verimliliği, Verimlilik analizi

\section{Investigation of the Effect of Using Pressure Booster on Air Compressor Efficiency}

\begin{abstract}
The rapidly developing economy in today's age brings along an increase in competition. Energy efficiency needs to be reviewed in order for businesses to get more efficient results. Energy efficiency can be defined as minimizing the excessive energy consumption per product in enterprises. For many businesses, it is a mandatory requirement for the operation of compressed air systems, so efficient use of compressed air is very important.

In this article, as a result of measurements about the efficiency of the compressed air system in an automotive factory, it has been studied how to use air more efficiently for product tests that require high pressure. How air booster use affects air compressor efficiency has been investigated.
\end{abstract}

Keywords: Compressed Air Compressors, Pressure Booster, Energy Efficiency, Efficiency analysis

\section{Giriş}

Basınçlı hava üretimi, atmosferde bulunan havanın bir kompresör mekanizması ile sıkıştılması ve depolanması işlemidir. Basınç lı hava, makine, ekipman ve işlemleri çalıştırmak için kullanılan saklanmış bir enerji türüdür [1]. Fabrikalarda şebeke basıncının sürekliliği için kompresör sisteminin set değer aralıklarında aktif olması istenir. Basınçlı havanın hammaddesi atmosferde bulunan havadır. Basınçlı havanın ilk yatırım maliyeti yüksektir. Bunun yanında çalıştırma maliyeti de, elektrikli aletlere göre daha fazladır. Ancak

\footnotetext{
* Duran Arif Göçer: Yıldız Pul Otomotiv Motor Parçaları Sanay A.Ş. ， Konya, Türkiye (ORCID: 0000-0002-2215-1542), duranarifgocer@yildizpul.com.tr
} 
çalıştırdığı aletler doğru koşulda çalıştırılır ise bu fark ortadan kaldırılır [1]. Bazı önlemlerin alınması ile çalıştırma maliyeti azaltılır ve hava kullanımı daha verimli hale gelir.

Bu çalışmada, bir otomotiv sanayisinde hava verimliliği üzerinde deneysel çalışma yapılmıştır. Fabrikada bulunan ekipmanlar 6 bar şebeke basıncı ile beslenmekte olup sistemler aktif edilmektedir. Şebeke basıncının yetersiz kaldığı test üniteleri ise ek bir elektrik kompresörü ihtiyacı ortaya çıkarmaktadır. İkinci bir kompresör kullanılması durumunda ek bir maliyet ortaya çıkmakta olup enerji kullanımıda bu ölçüde artış göstermektedir. Bu durumun önüne geçmek için ek bir kompresör kullanılmadan bir basınç yükseltici ile sistemin daha verimli çalışacağı üzerinde testler yapılmıştır.Sistemde var olan şebeke basıncı kullanılarak basınç yükselticinin giriş portu beslenmiştir. Basınç yükselticinin çıkış portu ise test edilecek ürünün çalışma basıncına göre ayarlanmıştır (12 bar). Yapılan testler basınç yükseltici ile kompresörün bir bir ürün testi sırasında kullandıkları hava miktarına göre yapılmış olup kompresörün kullandığı enerji hesaplanmıştır.

M.Altug KARATAŞ ve ekibi bir çelik fabrikasında basınçlı hava sisteminin verimliliği konusunda ölçümler yapmıştır. Fabrikada 3 adet kompresör dairesi bulunmakta olup bununla birlikte hava depoları ve bağlantı yolları bulunmaktadır. Ölçümler sonucunda havanın hangi noktalarda, ne miktarda ve nasıl tüketildiği incelenmiş, yapılabilecek iyileştirmeler ve enerji tasarruf olanakları belirlenmiştir [2]. Süleyman SAPMAZ ve ekibi, 3 farklı sanayi tesisinin basınçlı hava sistemleri enerji verimliliği açısından değerlendirilmişlerdir. Çalışma ile enerji tasarrufu ve emisyon azaltımı sağlanan başlıca uygulamalar tespit edilmiştir. Bunlar ise kompresörün atık ısısından faydalanılması, basınçlı hava hatlarındaki kaçakların önlenmesi, kompresör emiş havasının daha serin olması (sıcaklık debi akışını ters orantıda etkiler), kompresör motorunun daha verimli bir motor ile değiştirilmesidir [3]. Yang ve ekibi, kompresör sisteminde yapılan bir enerji sınıfı ile Vietnam'da bulunan bir tesis için elde edilecek kazançları hesaplamıştır. Uzun vadeli enerji politikasına uyum sağlamak için çalışma yapılmıştır. Tesisin enerji kayıplarının kompresör sisteminin optimize edilmemiş olmasından ve kaçaklardan kaynaklandığı tespit edilmiştir [4]. Kaya ve arkadaşları, basınçlı hava sisteminde bazı potansiyel tasarruf kalemlerine ait hesap yöntemlerini vermiş ve bir sanayi kuruluşunda elde edilebilecek kazanım miktarlarını hesaplamışlardır. Bu çalışmada, mevcut basınçlı hava sistemlerinde bazı modifikasyonlarla enerji maliyetinin nasıl azaltılacağı da ortaya konulmuştur [5].

Yapılan literatür taramasında ulaşılan çalışmalar genellikle kompresör tasarımına ait geliştirmeleri ve kompresörlerde yapılabilecek enerji kazanımlarına ilişkin hesap yöntemleri açıklanmaktadır. Aslında hedef minimum kapasite ve enerji kullanımı ile maksimum iş yapılmasının önemidir [6]. Aşağıdaki çalışamada ise farklı olarak sistemde basınç yükseltici kullanılarak verimlilik hesabı yapılmıştır. Kompresörden üretilen hava ile basınç yükselticiden karşılanan hava debileri karşılaştırılıp sonuçlar grafikselleştirilmiş̧ir

\section{Materyal ve Metot}

Testler firmada kullanılan DEWESOFT'a ait DEWE 43 veri toplama modulü ile yapılımıştır. Havanın debi ölçümü için ise SICK FTMg debiölçer kullanılmıştır. Sensör doğrulaması için firma bünyesinde üretilen kompresör test cihazında bulunan ABB FMT430 debimetre ile değerler karşılaştırılmış olup verilerde sapma gözlemlenmemiştir. DEWESOFT ortamında veriler incelenip grafiksel olarak analiz yapılmıştır.

\subsection{DEWE-43 Veri Toplama Modülü}

Cihaz voltaj ve tam köprü sinyallerinin dışında DSI adaptörlerinin kullanımı ile birlikte, IEPE, şarj, termokupllar, yarım köprü, çeyrek köprü, RTD, akım, direnç ve LVDT sinyallerini de kayıt edebilir. Örnekleme oranı, kanal başına saniyede 200kHz'dir.Yüksek hız CAN bağlantısı mevcuttur [7].

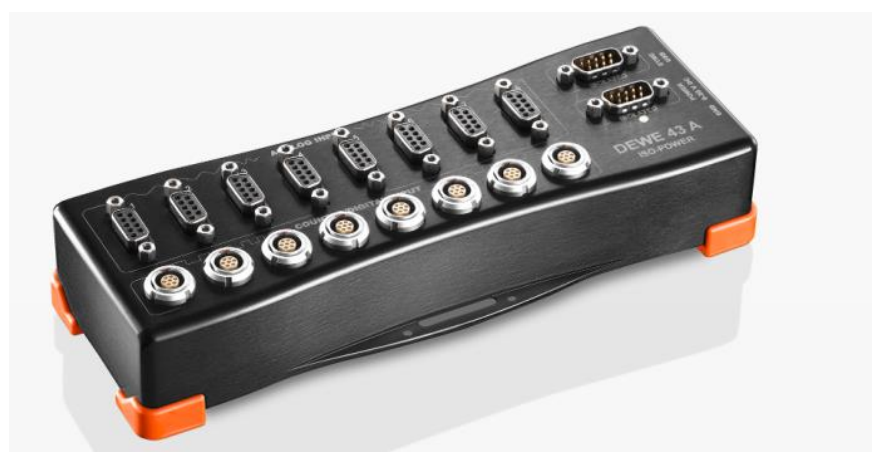

Şekil 2.1. DEWE-43 Veri Toplama Modülü [8]

\subsection{SICK FTMg Akış Sensörü}

SICK FTMg debimetreye ait teknik veriler Tablo 1.'de verilmiştir. 
Tablo 1. SICK FTMg Teknik Veriler [9]

\begin{tabular}{|c|c|}
\hline Ölçüm Prensibi & Kalorimetrik(akış,sıcaklık), piezorezitif(basınç) \\
\hline Ortam & Basınçlı hava,Helyum,Argon,Azot, Karbondioksit \\
\hline Bağlantı Ölçüsü & DN 25 \\
\hline \multirow[t]{2}{*}{ Ölçüm Aralı̆̆ } & 14,7l/min-2.945,2 I/min(standart ölçüm) \\
\hline & 2.945,2 I/min-4.417,9 I/min(gelişmiş ölçüm) \\
\hline Sicaklık Aralı̆̆g & $\left(-20^{\circ} \mathrm{C}\right)-\left(+60^{\circ} \mathrm{C}\right)$ \\
\hline Basınç Aralı̆̆g & $0-16$ bar \\
\hline Haberleşme & Ethernet TCP/IP \\
\hline Sicaklık Ölçümü & $\checkmark$ \\
\hline Basınç Ölçümü & $\checkmark$ \\
\hline
\end{tabular}

\section{Araştırma Sonuçları ve Tartışma}

\subsection{Basınç Yükseltici(booster) Set Basıncı}

Çalışmada ek bir kompresör yerine şebekede var olan düşük basıncı daha az enerji kullanarak yükseltmek olduğu için testler iki adımda yapılmıştır. Test sırasında kullanılan bağlantı elemanları aynı ölçüde olup testler yapılırken farklı boyutta bağlantı elemanı kullanılmamıştır. Testin ilk adımında sistemde bulunan ve test cihazına giden şebeke hattına ( 6 bar) bir debimetre bağlantısı yapılmıştır. Debimetreden hemen sonra ise basınç yükseltici (booster) kullanılıp çıkış basıncı 12 bara setlenmiştir. Basınç yükseltici set değeri kontrol edildikten sonra basınç yükseltici çıkış portuna bir debimetre daha eklenmiştir. Bu şekilde basınç yükseltici giriş ve çıkısındaki debi akış farkı gözlemlenmiş olup basınç yükselticinin verimliliği hesaplanmıştır. 10 saniyelik test boyunca 6 bar hava 12 bar basınca yükseltilmiş olup 12 bara yükseltmek için kullanılan hava miktari bulunmuştur. Şekil 3.1. 'de basınç yükselticinin giriş ve çıkış portundaki basınç değerleri aşağıdaki gibidir.

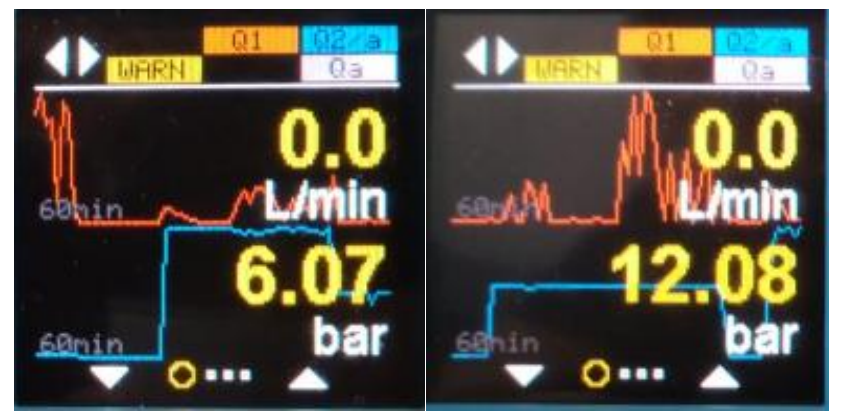

Şekil 3.1. Basınç Yükseltici Giriş-Çıkış Basınç Değerleri

\subsection{Basınç Yükseltici-Test Cihazı Deney Düzeneği}

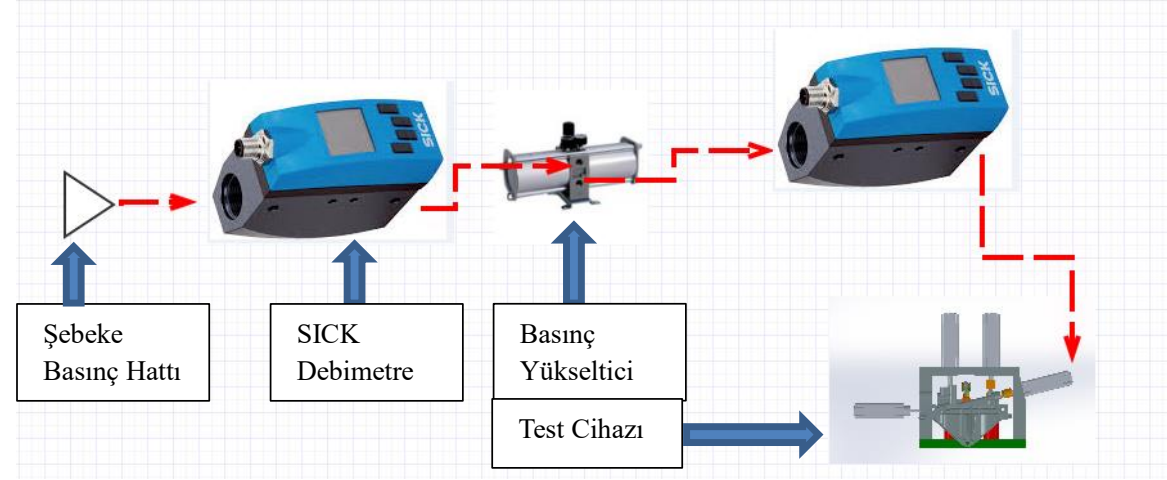

Şekil 3.2. Bağlantı Şeması 
Testin ilk adımı için yapılan mekanik bağlantı Şekil 3.2.'de verilmiştir. Testin ilk adımında anlatıldığı şekilde test cihazı üzerinde 10 saniye boyunca ürün için test yapılmış olup veriler aşağıdaki gibidir;

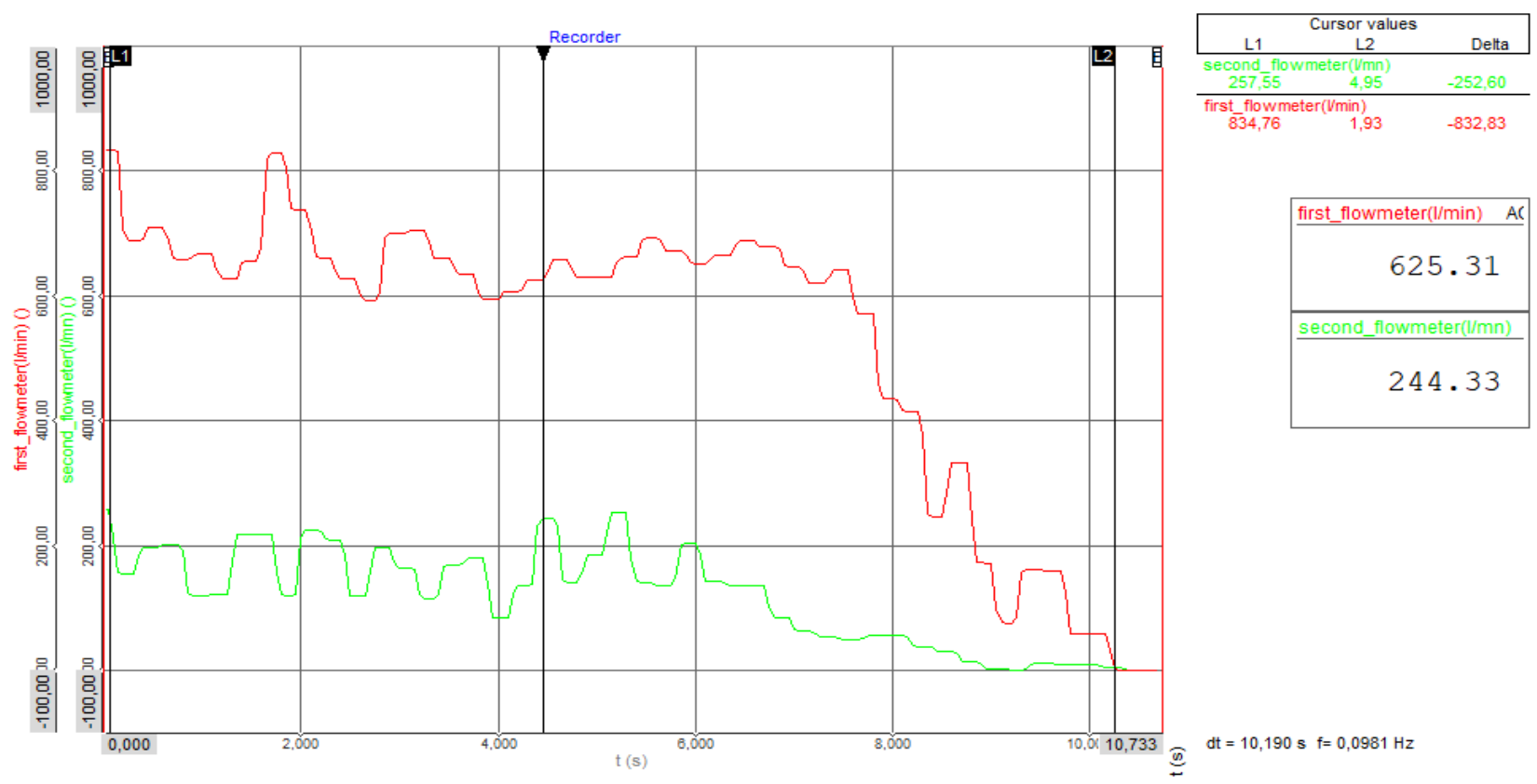

Şekil 3.3. Basınç yükseltici Giriş-Çıkış Hava Debi

Yukarıda verilen Şekil 3.3.'deki grafikte first_flowmeter basınç yükseltici ile şebeke arasındaki debimetreyi temsil etmektedir. Second_flowmeter ise basınç yükselticinin çıkışı ile test cihazı arasındaki debimetreyi temsil etmektedir. 10 saniyelik test boyunca 20 $\mathrm{kHz}$ de veri alınmış olup test anındaki anlık debi değişimleri gözlemlenmiștir. Kümülatif harcanan-kullanılan hava miktarları ise aşağıdaki gibidir;
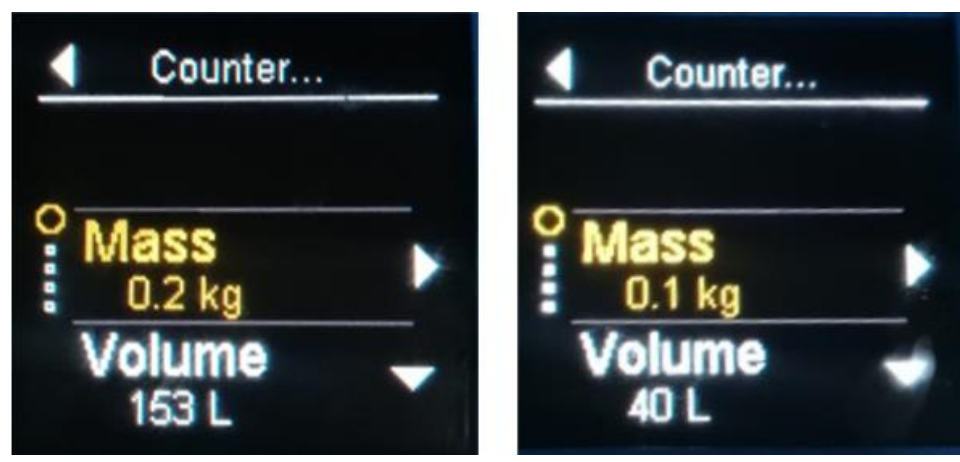

Şekil 3.4. First_Flowmeter ve Second_Flowmeter

Bir ürünün 10 saniyelik testi için basınç yükseltici 40 litrelik hava kullanımı için 153 litre hava harcamıştır.

Basınç yükseltici verimliliğ i $=(40 / 153) * 100=\% 26$

\subsection{Elektrik Kompresörü-Test Cihazı Deney Düzeneği}

İkinci adımda ise firmada bulunan elektrik kompresörü üzerinden bağlantı yapılarak kompresörün 6 bardan 12 bara yükselmesi sırasındaki güç hesabı yapılmış ve doldurma süresi ölçülmüştür. Tespit edilen veriler ile enerji hesabı yapılmıştır.

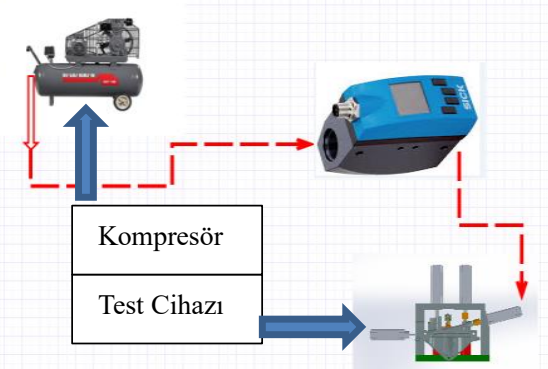


Şekil 3.5. Bağlantı Şeması

Şekil 3.5. 'de verilen şemada elektrik kompresörü-test cihazı arası bağlantı yapılmış olup test için gerekli 12 bar hava ihtiyacı elektrik kompresörüne ait tanktan karşılanmıştır. Öncelikle elektrik kompresörü çalıştırılarak tankın 6 bardan 12 bara istenilen test basıncına gelmesi beklenmiş daha sonra ise 10 saniyelik ürün testi gerçekleştirilmiştir. Kompresör tanka hava sıkıştırma esnasında toplamda 8 dakika yükte çalışarak anlık $2,5 \mathrm{~kW}$ (Şekil 3.8.) güç tüketmiştir. Tankın hacmi ise $250 \mathrm{~L}$ ' dir. Ürün testine ait grafik aşağıdaki gibidir;

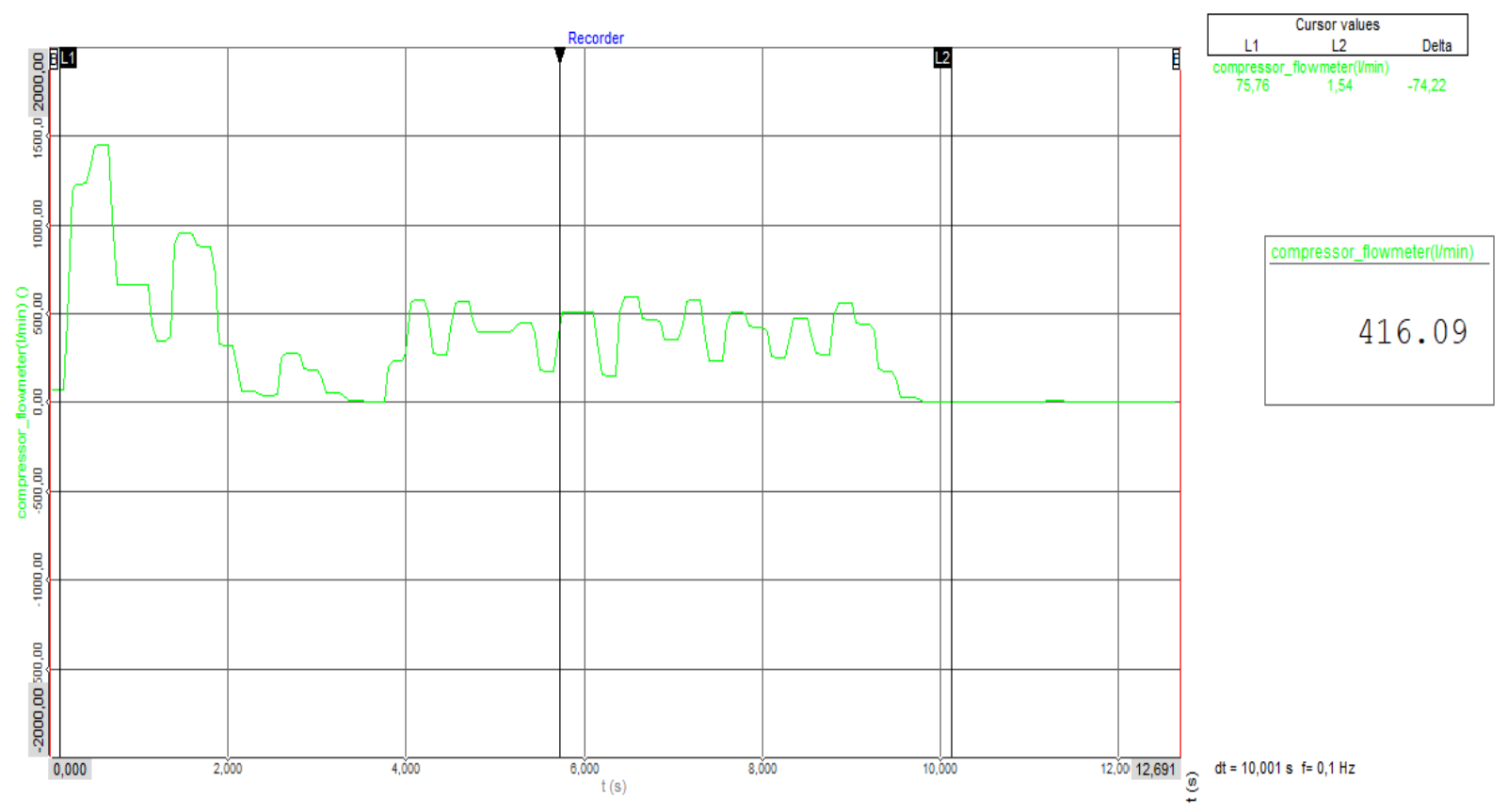

Şekil 3.6. Elektrikli Kompresör Çıkış Debi

İkinci test düzeneğinde hava akışı tanktan sağlandığı için bir adet debimetre kullanılmıştır. Bağlantı şeması Şekil 3.5.'de verilmiştir. Veri alma hızı testin ilk adımında olduğu gibi 20 kHz'dir. Test anında toplamda kullanılan hava miktarı aşağıda verilmiştir.

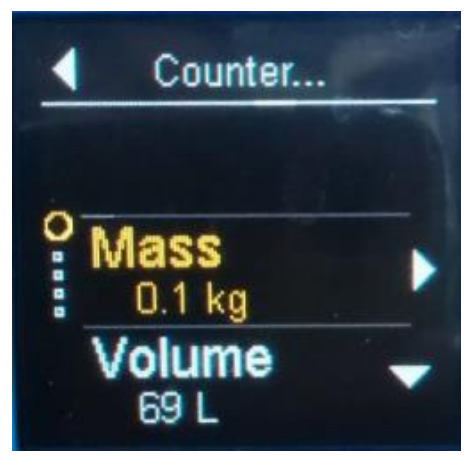

Şekil 3.7. Compressor_flowmeter

10 saniyelik test boyunca kümülatif $69 \mathrm{~L}$ hava tüketilmiştir.

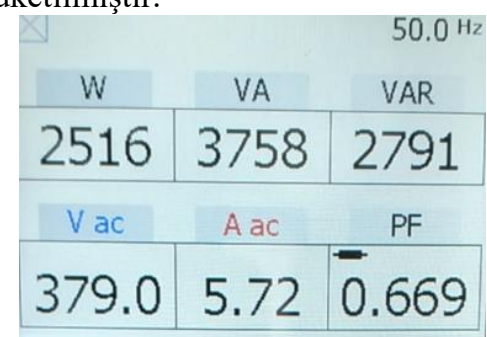

Şekil 3.8. Kompresör Güç Tüketimi 
$=(2,516 * 480)=1207 \mathrm{~kJ}$

Kompresörün 6 bardan 12 bara kadar yükseltilmesi çin 1207 kJ enerji gerekmektedir. Teorik dogrulama güç hesabı için aşağıdaki gibidir:

P.V $=$ m.R.T

$\mathrm{T}=273+30=303 \mathrm{~K}$

$\mathrm{P}_{1}=6$ bar=600kPa $\mathrm{P}_{2}=1200 \mathrm{kPa}$

$\mathrm{P}_{\mathrm{atm}}=100 \mathrm{kPa}$

6 bar için $\mathrm{m}_{1}=2,01 \mathrm{~kg}$

12 bar için $\mathrm{m}_{2}=3,73 \mathrm{~kg}$

6 barlık diferansiyelde kütle miktarı $=1,72 \mathrm{~kg}$

8 dakikalık kompresörün çalışması sonucu tanka 1600 litre hava depolamıştır. Test anında ise tanktan 69 litre hava kullanılmıştır. Sistem verimliliği $(69 / 2000) * 100=\% 3$

Kompresörün 11 bardan 12 bara 1 bar seviyesinde yükseldiğini hesap edersek toplamda 1 bar diferansiyelde 325 L hava depolar. 1 bar diferansiyelde verimlilik aşağıdaki gibidir;

$(69 / 325) * 100=\% 21$

Sonuçlar göz önüne alınıp değerlendirildiği zaman ise basınç yükseltici kullanılarak elektrik enerjisinden tasarruf edildiği net olarak görülmektedir.

Yapılan literatür taramasında çalışmalar genellik ile sistemlerde bulunan kaçaklara yönelik olup kompresörün nasıl daha verimli çalışacağı üzerinedir. Bu çalışmada ise şebekeyi besleyen kompresör haricinde ek kompresör kullanımını engelleyip yüksek basınç gerektiren test ünitelerini basınç yükseltici ile beslemek amaçlanmıştır. Ek kompresörün verimliliği ile basınç yükseltici verimliliği hesap edilip sonuçlar yorumlanmıştır.

\section{Sonuç}

Bu çalışmada şebeke hava hattı bulunan fabrikalar için şebeke basıncından yüksek basınç gerektiren test cihazları vb. uygulamalarda ek kompresör kullanımı veya basınç yükseltici kullanımı sonucunda verimlilik üzerine çalışma yapılmış olup veriler incelenmiştir. İncelenen verilere göre yüksek basınç (12 bar) gereken kısımlarda ek kompresör kullanmak yerine basınç yükseltici kullanılmasının elektrik enerjisinden \%100 kazanç sağladığı tespit edilmiştir. Basınç yükseltici 6 bardan 12 bar basıncı kontrol ederken bu işlemi mekanik olarak gerçekleştirmektedir. Kompresör ise motordan aldığı güç sayesinde basıncı artırmaktadır. Bunun içinde elektrik enerjisinden faydalanır. Çalışma sonucunda kompresörün 6 bar basınçtan 12 bar basınca yükselmesi sırasında harcanan enerji $1207 \mathrm{~kJ}$ olarak hesaplanmıştır. Basınç yükseltici ise bu enerji harcamasını tamamen ortadan kaldırmaktadır. Bu sebeble bir kompresör yerine basınç yükselticinin sistemde daha verimli olduğu testler sonucu tespit edilmiştir.

\section{Kaynakça}

[1] <https://docplayer.biz.tr/14243358-Basincli-hava-sistemleri.html >, erişim tarihi 06.09.2020.

[2] M.Altug KARATAŞ.2012 "Basınçlı Hava Sistemlerinde Enerji Verimliliği: Bir Çelik Fabrikasının Basınçlı Hava Denetleme Çalışması,”, Tesisat Mühendisliği - Sayı 132 - Kasım/Aralık

[3] Süleyman Sapmaz.2017 "Basıç̧lı Hava Sistemlerinde Enerji Verimliliği ve Emisyon Azaltım Fırsatlarının İncelenmesi,", Engineer and Machinery vol 58, no 689, p. 23-36

[4] Yang, M. 2009. “Air Compressor Efficiency in a Vietnamese Enterprise," Energy Policy, vol. 37 (6), p. $2327-2337$.

[5] Kaya, D., Phelan, P., Chau, D., Sarac, H. I. 2002 "Energy Conservation in Compressed-Air Systems," International Journal of Energy Research, vol. 26, p. 837-849.

[6] Güleç, M. 1999. "Pnömatik Sistemlerde Tasarruf Önlemleri ve Yöntemleri," MMO I. Ulusal Hidrolik Pnömatik Kongresi ve Sergisi, 3-5 Aralık 1999, İzmir-Türkiye.

[7] <https://rmc.com.tr/dewe-43/>, erişim tarihi 9.09.2020.

[8] <https://dewesoft.com/products/daq systems/dewe-43>, erişim tarihi 9.09.2020.

[9] <https://www.sick.com/tr/en/fluid-sensors/flow-sensors/ftmg/c/g505155>, erişim tarihi 9.09.2020. 